\title{
Changes in DNA methylation are associated with the development of drug resistance in cervical cancer cells
}

\author{
Chih-Cheng Chen ${ }^{1,2}$, Kuan-Der Lee ${ }^{1,2}$, Mei-Yu Pai ${ }^{3}$, Pei-Yi Chu ${ }^{4}$, Chia-Chen Hsu ${ }^{3}$, Chia-Chen Chiu ${ }^{1,2,3}$, \\ Li-Tzong Chen ${ }^{5}$, Jang-Yang Chang ${ }^{6}$, Shu-Huei Hsiao ${ }^{3}$ and Yu-Wei Leu ${ }^{3 *}$
}

\begin{abstract}
Background and propose: Changes in DNA methylation are associated with changes in somatic cell fate without the alteration of coding sequences. In addition to its use as a traceable biomarker, reversible DNA methylation could also serve as a therapeutic target. In particular, if the development of drug resistance is associated with changes in DNA methylation, then demethylation might reverse the resistance phenotype. The reversion of the drug-resistance might then be feasible if the association between abnormal DNA methylation and the development of drug-resistance could be identified.
\end{abstract}

Methods: Methylation differences between the drug-resistance cervical cancer cell, SiHa, and its derived oxaliplatinresistant S3 cells were detected by methylation specific microarray. The drug-resistance cells were treated with demethylation agent to see if the resistance phenotype were reversed. Targeted methylation of one of the identified locus in normal cell is expected to recapitulate the development of resistance and a two-component reporter system is adopted to monitor the increase of DNA methylation in live cells.

Results: In this report, we identified methylation changes, both genome-wide and within individual loci, in the oxaliplatin-resistant cervical cancer cell S3 compared with its parental cell line SiHa. Treatment of S3 with a demethylation agent reversed increases in methylation and allowed the expression of methylation-silenced genes. Treatment with the demethylation agent also restored the sensitivity of S3 to cisplatin, taxol, and oxaliplatin to the same level as that of SiHa. Finally, we found that methylation of the target gene Casp8AP2 is sufficient to increase drug resistance in different cells.

Conclusions: These results suggest that global methylation is associated with the development of drug resistance and could serve as a biomarker and therapeutic target for drug resistance in cervical cancer.

Keywords: DNA methylation, DRUG, Cancer

\section{Background}

DNA methylation is a stable, dominant, and inheritable epigenetic modification that silences genes in somatic cells [1-3]. Through DNA methylation, environmental factors such as growth factors, food, and toxins can reshape the methylome and eventually differentiate

\footnotetext{
*Correspondence: bioywl@ccu.edu.tw

${ }^{3}$ Department of Life Science, Human Epigenomics Center, Institute of Molecular Biology and Institute of Biomedical Science, National Chung

Cheng University, Chiayi 621, Taiwan

Full list of author information is available at the end of the article
}

or transform a cell $[4,5]$. For example, knockdown of upstream estrogen receptors (ERs) increases methylation within ER target genes [6]. Also, various concentrations of diets given to pregnant mice can lead to production of the methylation source $S$-adenosylmethionine (SAM), altering methylation level at the promoter regions of fur color reporter genes and causing variegated fur color in the offspring [7-9]. Furthermore, environmental toxins such as endocrine disrupters can change methylation states through different signaling pathways $[10,11]$. All of 
these examples demonstrate that the methylome is subject to further modifications.

Changes in the methylome are associated with cellular transformation [2, 12-14]. Dramatic methylome changes can be initiated early during the production of germ line cells and even before implantation [15, 16]. Particular changes of the methylome are associated with the specification of different cell lineages during development $[17,18]$. Deviating from a normal state, abnormal global hypomethylation or hypermethylation of tumor suppressor genes can induce cancer as revealed by genetic studies $[19,20]$. The accumulation of abnormal DNA methylation can be found after tumor formation, metastasis, and the development of drug resistance, although it's not easy to form connections between particular changes in methylation and specific transformation events [21].

Several changes in DNA methylation may affect cellular sensitivity to drug treatment. For example, increased DNA methylation within $B R C A 1$ promoter in ovarian cancer patients correlate with better platinum-based chemotherapy [22]. By contrast, hypermethylation of $M L H 1$ is associated with increased cisplatin resistance in an ovarian cancer cell line [23]. Also, hypermethylated $D A P K$ in colon and breast cancers correlates with drug resistance $[24,25]$. DAPK works through the tumor necrosis factor-related apoptosis-inducing ligand (TRAIL). Hypermethylation within the TRAIL gene correlates with drug resistance in lung cancer [26], and the reversal of TRAIL methylation by methylation inhibitor treatment restores sensitivity to drug treatment [27-29]. These findings suggest that abnormal DNA methylation might affect cell death pathways and the development of drug resistance in cancer [30, 31].

Identifying the methylation changes related to drug resistance might provide a diagnostic clue as to whether the development of drug resistance is methylationdependent. Also, if changes in DNA methylation are sufficient to cause drug resistance in cancer, then the reversal of these changes might restore the sensitivity of cancer cells to drug treatment. In this report, we characterized the SiHa cancer cell-derived oxaliplatinresistant cervical cancer cell line S3 [32]. Treatment with a methylation inhibitor reversed drug resistance, indicating that the development of resistance is methylationdependent [33]. Differential methylation hybridization (DMH) microarray was performed to detect methylation changes associated with the development of drug resistance $[34,35]$. Previously, demethylation of these target loci restored the expression of the target genes and their sensitivities to different cancer drugs [36-39]. Finally, we applied a two-component system to monitor DNA methylation of the identified target gene $[17,40]$ Casp $8 A P 2$ (NM_001137667) and found that increased methylation was associated with a drug-resistant phenotype. These findings suggest the possibility of identifying changes in methylation that are related to drug resistance in cancer.

\section{Methods}

\section{Cell culture, isolation, and characterization}

Human mesenchymal stem cells (MSCs) were isolated and cultured as described by Lee et al. [41], and cell expansion was as described by Hsiao et al. [17, 41]. MDA-MB-231, SiHa, and S3 cells were cultured with L-15, Minimum Essential Medium (MEM; Invitrogen), and MEM with $2 \mu \mathrm{g} / \mathrm{ml}$ oxaliplatin, respectively. For all cells, the medium was supplemented with $10 \%$ fetal bovine serum (Invitrogen), $100 \mathrm{mg} / \mathrm{ml}$ penicillin/streptomycin (Invitrogen), and $2 \mathrm{mM} \mathrm{L-glutamine} \mathrm{(Invitrogen).}$

\section{5-Aza-2'-deoxycytidine (5-Aza) treatment}

Cells were treated with $5 \mu \mathrm{M} 5$-aza or an equal volume of DMSO as a control for 5 consecutive days.

\section{Cloning of the human Casp8AP2 promoter}

Primers for the human Casp8AP2 promoter are listed in Additional file 1: Table S1. Human MSC genomic DNA was used as a polymerase chain reaction (PCR) template. Purified PCR products were ligated into the pyTEA cloning vector (Yeastern Biotech) according to the manufacturer's protocol. Inserts were confirmed by restrictions and sequencing.

\section{In vitro DNA methylation}

PCR-amplified Casp8AP2 promoters $(4 \mu \mathrm{g})$ were incubated with 20 units of CpG methyltransferase (New England BioLabs) at $37^{\circ} \mathrm{C}$ for $4 \mathrm{~h}$ in the presence of $160 \mu \mathrm{M}$ SAM to induce methylation.

\section{Validation of in vitro DNA methylation}

Methylated DNA showing resistance to methylation-sensitive restriction enzymes (HpaII) was considered to indicate completed conversion (Additional file 1: Figure S1).

\section{Transfection of methylated DNA}

PCR products $(0.4 \mu \mathrm{g} / \mathrm{well}$, unmethylated as a control) were denatured at $95{ }^{\circ} \mathrm{C}$ and then transfected into $5 \times 10^{5}$ cells/well in a 6 -well plate using DMRIE-C (Invitrogen) according to the manufacturer's instructions. Cells were transfected three times, on day 1,3 , and $5[17$, 42]. The transfection efficiency and the localization of the transfected DNA were tracked as in Additional file 1: Figure S2.

\section{Bisulfite conversion}

Genomic DNA $(0.5 \mu \mathrm{g})$ was bisulfite-converted and purified as described by Yan et al. [43]. 


\section{Semi-quantitative real-time methylation-specific PCR (qMSP)}

The qMSP was performed as described by Yan et al. [43]. Bisulfite-converted genomic DNA was subject to realtime PCR with methylation-specific primers (Additional file 1: Table S1). A SYBR Green I PCR Kit (Toyobo) was used to conduct qMSP in an iQ5 PCR instrument (BioRad). After reactions, analysis of melting temperature was performed to ensure that a specific amplicon was generated. Col2A1 (NM_033150) was used for standard curve construction and as a loading control. Methylation percentage was calculated as: (mean of target gene)/ (mean of Col2A1). Fold change was calculated as: (targeted DNA methylation percentage)/(mock methylation percentage).

\section{Differential methylation hybridization microarray, DMH}

The DMH procedure was performed as described by Leu et al. [44] using a human CpG microarray (Agilent). Treated and control genomic DNA $(2 \mu \mathrm{g})$ was restricted into small fragments by MseI and ligated with designated primers. Methylation-sensitive restriction enzymes (Bst $\mathrm{UI}$ and HpaII) were used to discriminate between methylated and unmethylated DNAs, and DNAs was then amplified by PCR using adaptors as primers. PCRamplified DNA from mock-treated S3 cells was labeled with $\mathrm{Cy} 5$ and from SiHa or 5-aza-treated S3 cells was labeled with $\mathrm{Cy} 3$ and then co-hybridized onto slides. After scanning, the ratio between Cy5 and Cy3 dyes was normalized by locally weighted scatterplot smoothing. Significant methylation differences were identified.

\section{Semi-quantitative RT-PCR (qRT-PCR)}

RNA isolation, first-strand cDNA synthesis, and detection of transcripts were carried out as previously described [44]. Total RNA ( $2 \mu \mathrm{g})$ was reverse transcribed using SuperScript II reverse transcriptase (Invitrogen). qRT-PCR was performed using a SYBR Green I PCR Kit (Toyobo) in an iQ5 Real-Time instrument (Bio-Rad). A serial dilution of GADPH-amplified (NM_002046) cDNA was used as a control to generate a standard curve, and $G A P D H$ from each sample was used as a loading control. The primers used are listed in Additional file 1: Table S1.

\section{Cell survival assay}

Cells $\left(5 \times 10^{4}\right)$ were plated into each well of a 96-well assay plate and allowed to attach. Cells were then treated with different concentrations of drugs and incubated at $37{ }^{\circ} \mathrm{C}$ overnight. 3-(4,5-Dimethylthiazol-2-yl)-2,5-diphenyltetrazolium bromide (MTT) solution $(20 \mu \mathrm{l}, 5 \mathrm{mg} /$ $\mathrm{ml}$; Sigma) was added to each well and incubated at $37^{\circ} \mathrm{C}$ for $5 \mathrm{~h}$. The reaction was terminated by adding $100 \mu \mathrm{l}$ DMSO, and absorbance was measured at $595 \mathrm{~nm}$.

\section{Western blot analysis}

Cells were harvested in RIPA buffer, and proteins were separated in $10 \%$ polyacrylamide gel and trans-blotted onto a membrane. After blocking with skim milk, the membrane was hybridized with designated antibodies. After washing, secondary antibody conjugated with horseradish peroxidase was used to detect hybridization. Results were visualized by chemiluminescence. The film was then scanned and analyzed.

\section{Immunostaining}

Treated or control cells $\left(5 \times 10^{4}\right)$ were plated into 4-well chamber slides and allowed to attach. After washing and fixing in $2 \%$ formaldehyde, cells were again washed and permeabilized by $0.5 \% \mathrm{NP} 40$ in phosphate-buffered saline (PBS). After another wash, horse serum in PBS (1:100) was used to block, and the slides were washed. Specific antibodies were used to stain the cells, and fluorescein-conjugated secondary antibodies were used to detect the staining. The slides were mounted, and cells were visualized using a fluorescent microscope.

\section{Enzyme-linked immunosorbent assay (ELISA)}

Green fluorescent protein (GFP) ELISA was performed using an ELISA Kit (Cell Biolabs) according to the manufacturer's instructions. Starting from $2 \times 10^{4}$ cells per assay, the cells were harvested and lysed, and the collected proteins were quantified. Proteins $(0.1 \mu \mathrm{g} / \mathrm{ml}$ per assay) were compared with the provided standard after binding to GFP antibody, secondary antibody, and substrate solution with vigorous washes between steps. After stopping the reaction, absorbance was measured at $595 \mathrm{~nm}$.

\section{Results}

\section{Changes in DNA methylation and expression} in oxaliplatin-resistant cervical cancer S3 cells

A more than 40-fold decline in sensitivity was found for the oxaliplatin-resistant cervical cancer cell S3 compared with its parental SiHa cervical cancer cell line (Fig. 1a). The expression of several death-related genes decreased during the development of oxaliplatin resistance (Fig. 1b). This decreased expression of deathrelated genes, such as Casp8AP2, the detoxification gene $G S T p 1$, and the repair gene $M L H 1$, was associated with increased methylation within their promoter regions (Fig. 1c). These findings suggest that changes in epigenetic and DNA expression states are involved in the development of drug resistance.

\section{Global methylation changes in S3 cells}

Genome-wide changes in methylation during the development of drug resistance in S3 cells were detected by 

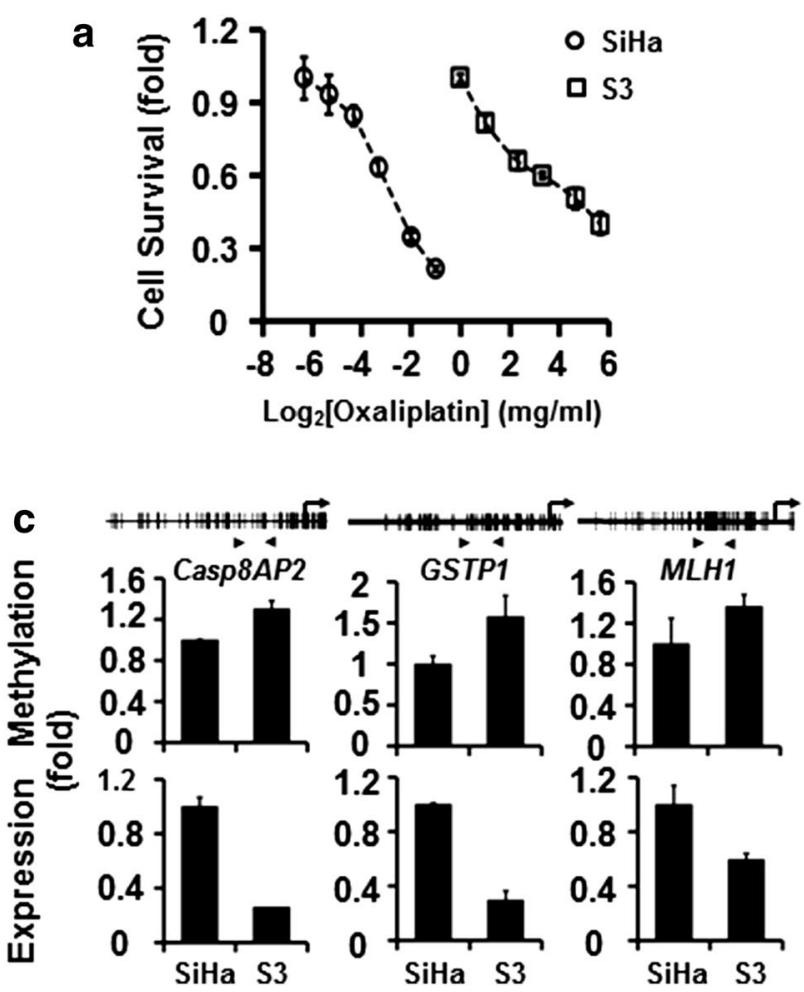

b

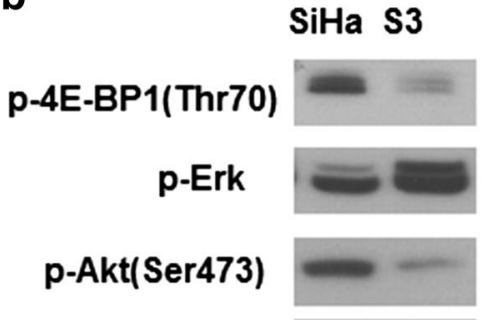

$\alpha$-Tublin

Akt

Actin

DNMT1

Actin

\section{Casp8AP2}

Actin

Fig. 1 Gene methylation and expression changes in S3 cells. a Survival of S3 and SiHa cells upon treatment with different concentrations of oxaliplatin as assessed by MTT assay. b Differences in gene expression between S3 and SiHa cells as revealed by protein levels in western blot analysis. c Differences in gene methylation and expression between S3 and SiHa cells. Methylation within the promoter regions (arrowheads) was measured by qMSP (upper panels). Corresponding changes in gene expression were detected by qRT-PCR (lower panel)

DMH. Changes in methylation were compared between S3 and SiHa cells (Fig. 2a, S1 and S2) as well as before and after 5-aza treatment in S3 cells (Fig. 2a, S3 and S4). After hierarchical clustering analysis of repeated DMH results, we found both increases (Fig. 2a, block I) and decreases (Fig. 2a, block III) in methylation within the S3 genome. Some of the increases in methylation were inhibited by 5 -aza treatment (block I), suggesting that these methylation changes are associated with the development of drug resistance. On the other hand, some increases in DNA methylation were observed after 5-aza treatment (block III), suggesting that these methylation changes are not involved in the development of drug resistance. Three primary target loci (NEUROG2, $P V T 1$, and $D L X 2$ ) identified from DMH analysis were validated together with the three known targets (Casp8AP2, GSTP1, and MLH1) as controls (Fig. 2b). S3 showed increased methylation within the promoter region and lower expression of these genes compared with $\mathrm{SiHa}$. This increased methylation (Fig. 2c, upper panel) and lower gene expression (Fig. 2c, lower) in S3 cells was reversed by 5 -aza treatment. Treatment with 5-aza also increased Casp8AP2 expression in S3 cells as detected by RT-PCR (Fig. 2c) and immunostaining (Fig. 2d, also detected by Western blot, Additional file 1: Figure S3).

\section{Demethylation and reversal of drug resistance in $\mathrm{S} 3$}

If increased DNA methylation in drug-resistant cancer cells is necessary for the maintenance of drug resistance, then the reversal of DNA methylation in S3 should restore their sensitivity to drug treatment. After 5-aza treatment, S3 lost their resistance to cisplatin and taxol (Fig. 3a, upper and lower panels, respectively). Also, after 5-aza treatment, the sensitivity of S3 cells to oxaliplatin was restored to the same level as that in untreated SiHa (Fig. 3b). Together, these findings indicate that the maintenance of methylation may be critical for the maintenance of drug resistance in cancer cells. 

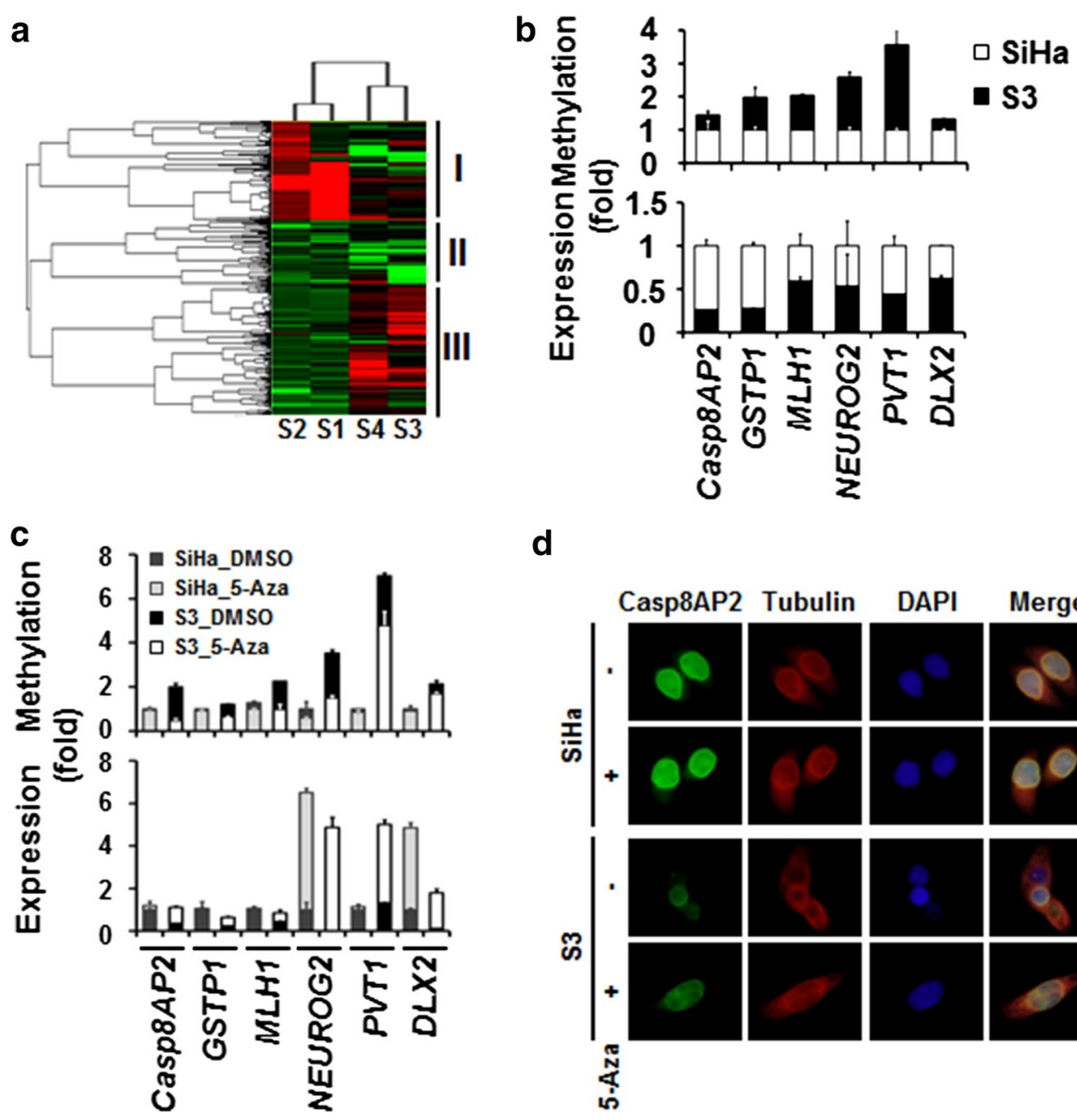

d

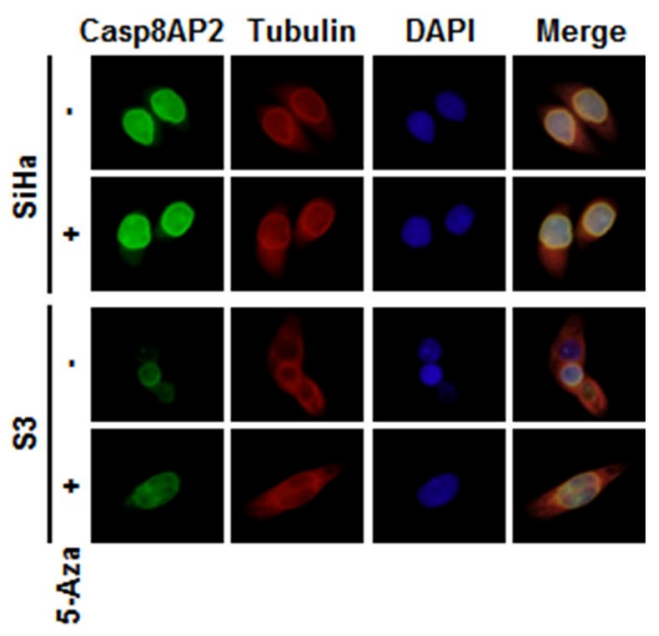

Fig. 2 Global methylation changes in S3 cells. a DMH microarray detected differences in genome-wide methylation between S3 and SiHa cells (S1 and S2) and between 5-aza-treated and -untreated S3 cells (S3 and S4). These four sets of data were then subject to unsupervised hierarchical clustering analysis. Blocks I, II, and III designate the main clustering blocks. b Validation of gene methylation and expression differences between S3 and SiHa cells. Three genes (NEUROG2, PVT1, and DLX2) with identified methylation differences from a were validated by qMSP, and changes in their expression were detected by qRT-PCR. Three genes (Casp8AP2, GSTP1, and MLH1) with known methylation and expression differences between S3 and SiHa cells were used as controls. cThese loci were hypermethylated in S3 cells, and their methylation was reversed (upper panel) and their expression restored (lower panel) by treatment with 5-aza. $\mathbf{d}$ Immunostaining confirmed the restoration of Casp8AP2 expression after treatment with 5-aza

\section{Visualization of the targeted Casp8AP2 methylation and increased drug resistance in cells}

To confirm that methylation of specific genes is sufficient to increase cellular drug resistance, we developed a twocomponent system to monitor methylated Casp $8 A P 2$. To visualize the targeted methylation of Casp8AP2, the Cas$p 8 A P 2$ promoter was cloned in front of the Tet repressor gene, and, on another vecor, Tet repressor binding sites TetO2 (Tet operator) were cloned in front of the enhanced GFP (EGFP) reporter (Fig. 4a). If Casp8AP2 is not methylated, the Tet repressor is expressed, binds to
TetO2 and suppresses EGFP expression. By contrast, the targeted methylation of Casp8AP2 suppresses Tet repressor gene expression and releases the suppression of EGFP expression. Using this system, Casp $8 A P 2$ methylation is reflected by increased levels of EGFP.

We chose both an upstream and downstream regions to targeted methylate Casp $8 A P 2$ (Fig. 4b, upper panel). We observed increases in Casp8AP2 methylation (Fig. 4b, center panel) and EGFP expression (Fig. 4b, lower panels) regardless of whether the far or near ends were targeted. The targeted CAsp $8 A P 2$ methylation was also evidenced 
a
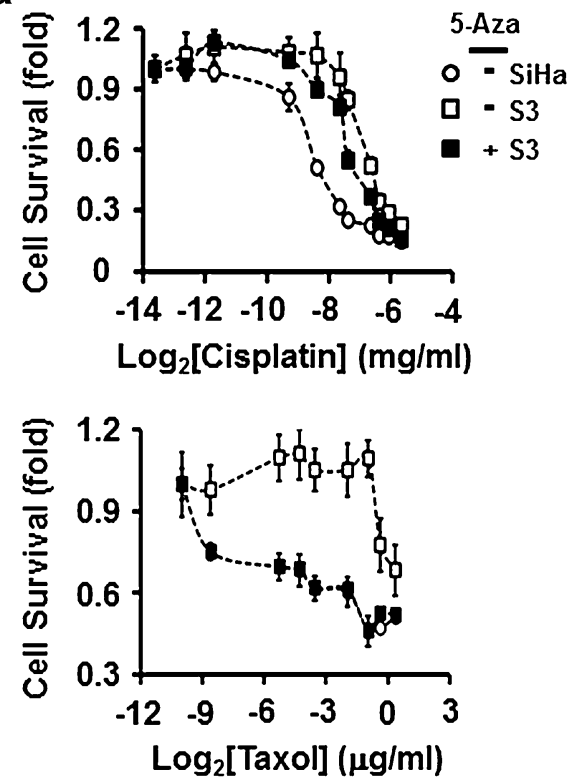

b

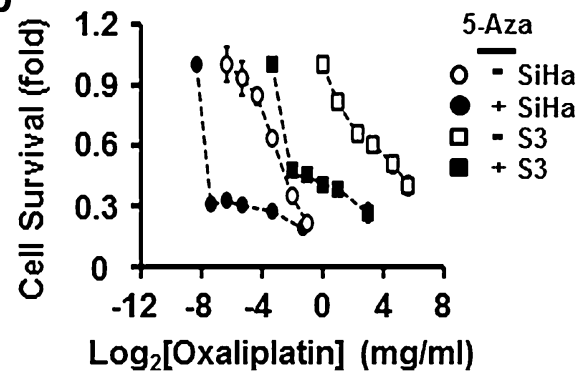

Fig. 3 5-Aza treatment reverses drug resistance in S3 cells. a After S3 cells were mock-treated or treated with 5-aza, they were treated with different concentrations of cisplatin (upper panel) or taxol (lower panel). Mock-treated SiHa cells were used as a control. Cell survival was measured by MTT assay. b S3 and SiHa cells were treated with 5 -aza to demethylate their DNA, and cells were then challenged with different concentrations of oxaliplatin. Cell survival was measured by MTT assay. The survival rates of untreated S3 and SiHa cells were included from Fig. 1 for comparison

by bisulfite sequencing (Additional file 1: Figure S4) Successful targeted DNA methylation increased the methylation (Fig. 4c, upper panels) and reduced gene expression (Fig. 4c, lower panels) of Casp8AP2 in both MSCs and the breast cancer cell line MDA-MB-231. Both cell lines became less sensitive to cisplatin and taxol after Casp8AP2 methylation (MDA-MB-231 cells: Fig. 4d; MSCs: Additional file 1: Figure S5).

\section{Discussion}

DNA methylation is an inheritable mark that could direct gene expression and cell fates $[45,46]$. Changes in DNA methylation often imply a detour in cell physiology and could serve as a way to further vary cellular transformation and clonal expansion [47, 48]. Accumulating data correlates abnormal DNA methylation with tumorigenesis, metastasis, and the development of drug resistance [47, 49]. Although genetic studies directly link abnormal DNA methylation to cellular transformation, how abnormal DNA methylation leads to the development of drug resistance is relatively unclear.

DNA methylation is a stable change, yet it is also reversible like other epigenetic modifications. Its stability makes methylation easy to detect, and its reversibility makes it a possible therapeutic target [50,51]. If methylation of a specific locus is sufficient to cause drug resistance, then detection of this modification might be used to monitor the development of drug resistance. Furthermore, if demethylation of a locus is closely related to the reversal of drug resistance, then it could be a candidate mechanism for restoring the sensitivity of cells to drug treatment. Therefore, we used DMH to identify several methylation changes occurring during the development of drug resistance. The loci that became hypermethylated and that showed a reversal of methylation after treatment with a demethylation agent could be primary targets [52].

In the present study, by establishing a two-component system for monitoring targeted DNA methylation and quantifying the degree of methylation, we found that targeted Casp8AP2 methylation caused the development of cellular drug resistance in different lines of cells. This monitoring system could be further used to monitor environmentally induced changes in methylation state and to track targeted cells in their microenvironments.

\section{Conclusion}

Global methylation changes are associated with the development of drug resistance in cervical cancer. Methylation inhibitors reverse the resistance-associated methylation increases and the resistance phenotype. Methylation changes might serve as a biomarker and therapeutic target for drug resistance in cervical carcinoma cells. 
a
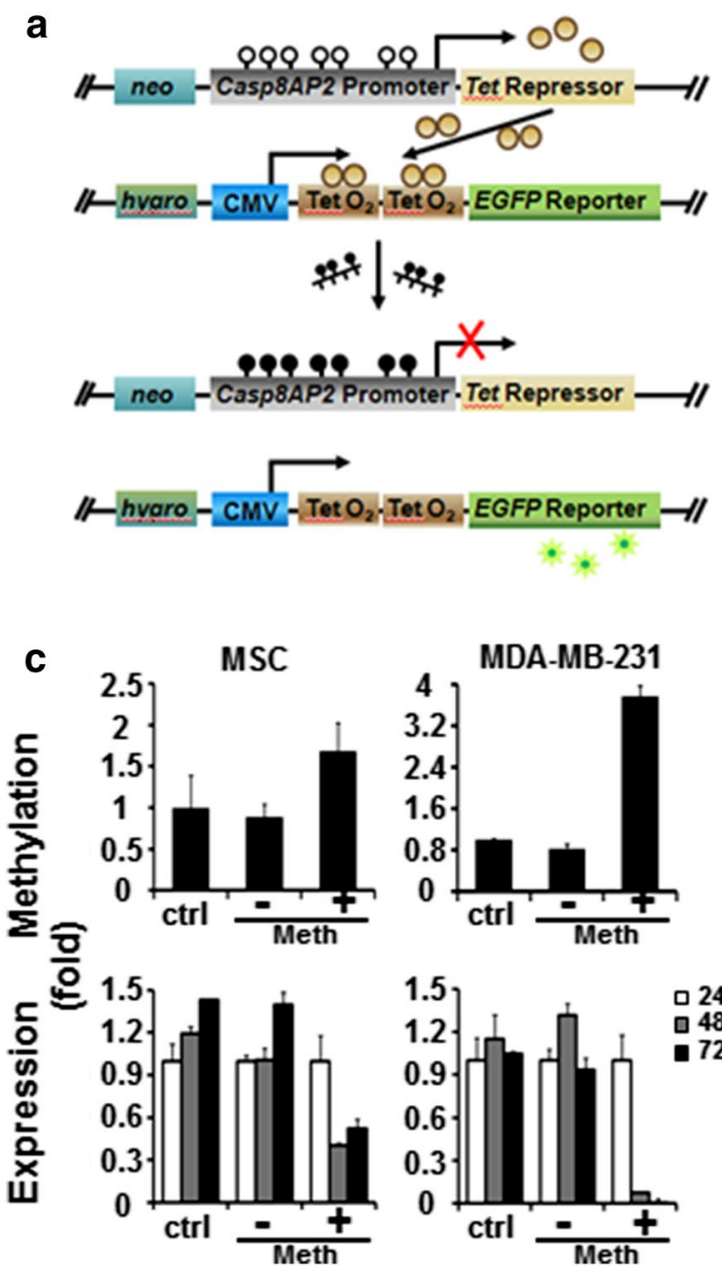

MDA-MB-231
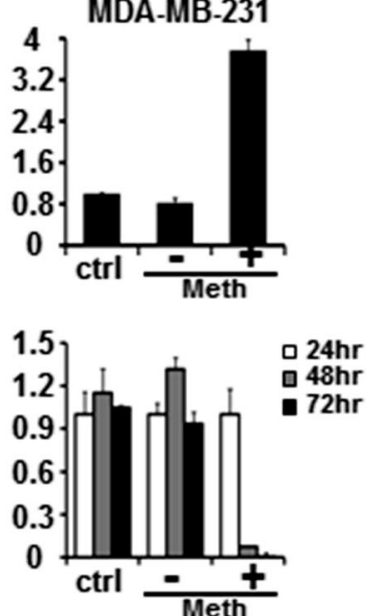

b

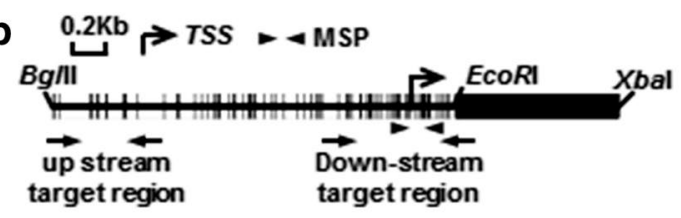

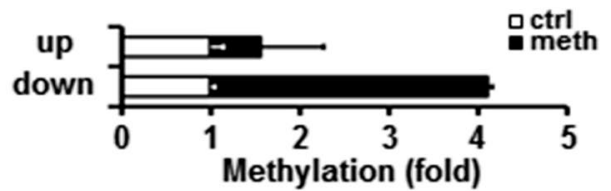

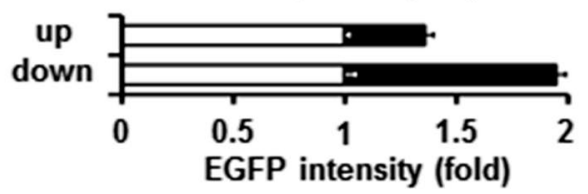

d

MDA-MB-231
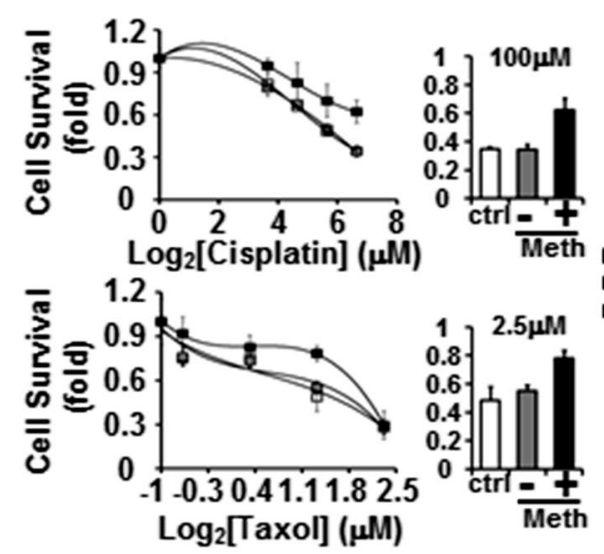

Meth $a c t r$ mock meth

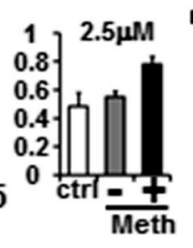

Fig. 4 Targeted Casp8AP2 methylation increases drug resistance. a Two-component system for visualizing targeted DNA methylation. Components were co-transfected into the same cells, and stable clones were selected by adding neomycin and hygromycin to the culture medium. Detection of targeted DNA methylation is described in the "Methods". b Detection of targeted DNA methylation. Upstream and downstream target regions are indicated by the regions between two arrows in the upper panel. Short vertical bars indicate CpG sites. Targeted DNA methylation was detected by GMSP with primer pairs (indicated by arrowheads in the upper panel), and mock-treated cells were used as a control (middle panel). Expression of the EGFP reporter gene was detected by ELISA (lower panel). c Increased Casp8AP2 methylation (upper panel) and decreased Casp8AP2 expression (lower panel) after targeted DNA methylation in MSCs (left) and MDA-MB-231 breast cancer cells (right). Untreated cells are designated as control (ctrl), and cells treated with transfection reagent only are designated as (-). d Increased cell survival after targeted Casp8AP2 methylation. MDA-MB-231 cells were transfected with in vitro methylated (S.ssl) or unmethylated Casp8AP2 DNA and then challenged with different concentrations of cisplatin (upper panel) and taxol (lower panel). Cell survival after drug treatment was detected by MTT assay

\section{Additional file}

Additional file 1. DNA methylation change is associated with the development of drug resistance in cervical cancer.

\section{Abbreviations}

5-Aza: 5-aza-2'-deoxycytidine; SAM: s-adenosyImethionine; MSC: mesenchymal stem cell.

\section{Authors' contributions}

CCC, MYP, KDL, PYC, CCC, SHH and YWL carried out the molecular studies. KDL isolate the MSC. LTC and JYC isolated the S3 cells. CCC, SHS and YWL drafted and finished the manuscript. All authors read and approved the final manuscript.

\section{Author details}

1 Department of Hematology and Oncology, Chang Gung Memorial Hospital, Chiayi, Chang Gung University College of Medicine, Taoyuan, Taiwan. ${ }^{2}$ Chang Gung Institute of Technology, Taoyuan, Taiwan. ${ }^{3}$ Department of Life Science, Human Epigenomics Center, Institute of Molecular Biology and Institute of Biomedical Science, National Chung Cheng University, Chiayi 621, Taiwan. ${ }^{4}$ Department of Pathology, Show Chwan Memorial Hospital, Changhua City, Taiwan. ${ }^{5}$ National Institute of Cancer Research, National Health Research Institutes, Zhunan, Miaoli County 350, Taiwan. ${ }^{6}$ Division of Hematology/ Oncology, Department of Internal Medicine, National Cheng Kung University Hospital, College of Medicine, National Cheng Kung University, Tainan 704, Taiwan. 


\section{Grant support}

YWL and CCC are supported by Chang Gung Memorial Hospital (CMRPG6B0521 and CMRPG6B0371). YWL and KDL are supported by MoST (MoST 103-2314-B-182A-090). YWL and SHH are supported by MoST (NSC 102-2320-B-194-003-MY3) and NHRI (NHRI-EX102-10259NI).

\section{Competing interests}

The authors declare that they have no competing interests.

Received: 25 September 2015 Accepted: 5 October 2015 Published online: 13 October 2015

\section{References}

1. Bird A. Perceptions of epigenetics. Nature. 2007;447(7143):396-8.

2. Baylin SB, Jones PA. A decade of exploring the cancer epigenome-biological and translational implications. Nat Rev Cancer. 2011;11(10):726-34.

3. Li E, Zhang Y. DNA methylation in mammals. Cold Spring Harb Perspect Biol. 2014;6(5):a019133.

4. Jaenisch $\mathrm{R}$, Bird A. Epigenetic regulation of gene expression: how the genome integrates intrinsic and environmental signals. Nat Genet. 2003;33(Suppl):245-54.

5. Kim M, Bae M, Na H, Yang M. Environmental toxicants-induced epigenetic alterations and their reversers. J Environ Sci Health C Environ Carcinog Ecotoxicol Rev. 2012;30(4):323-67.

6. Leu YW, Yan PS, Fan M, Jin VX, Liu JC, Curran EM, Welshons WV, Wei SH, Davuluri RV, Plass C, et al. Loss of estrogen receptor signaling triggers epigenetic silencing of downstream targets in breast cancer. Cancer Res. 2004;64(22):8184-92.

7. Waterland RA, Jirtle RL. Transposable elements: targets for early nutritional effects on epigenetic gene regulation. Mol Cell Biol. 2003;23(15):5293-300.

8. Dolinoy DC, Weidman JR, Waterland RA, Jirtle RL. Maternal genistein alters coat color and protects Avy mouse offspring from obesity by modifying the fetal epigenome. Environ Health Perspect. 2006;114(4):567-72.

9. Dolinoy DC, Weidman JR, Jirtle RL. Epigenetic gene regulation: linking early developmental environment to adult disease. Reprod Toxicol. 2007;23(3):297-307.

10. Hilakivi-Clarke L. Maternal exposure to diethylstilbestrol during pregnancy and increased breast cancer risk in daughters. Breast Cancer Res. 2014;16(2):208

11. Radford EJ, Ito M, Shi H, Corish JA, Yamazawa K, Isganaitis E, Seisenberger S, Hore TA, Reik W, Erkek S, et al. In utero effects. In utero undernourishment perturbs the adult sperm methylome and intergenerational metabolism. Science. 2014;345(6198):1255903.

12. Kulis M, Esteller M. DNA methylation and cancer. Adv Genet. 2010;70:27-56.

13. Siegel EM, Riggs BM, Delmas AL, Koch A, Hakam A, Brown KD. Quantitative DNA methylation analysis of candidate genes in cervical cancer. PLoS One. 2015;10(3):e0122495.

14. Farkas SA, Milutin-Gasperov N, Grce M, Nilsson TK. Genome-wide DNA methylation assay reveals novel candidate biomarker genes in cervical cancer. Epigenetics. 2013;8(11):1213-25.

15. Smith ZD, Chan MM, Humm KC, Karnik R, Mekhoubad S, Regev A, Eggan K, Meissner A. DNA methylation dynamics of the human preimplantation embryo. Nature. 2014;511(7511):611-5.

16. Messerschmidt DM, Knowles BB, Solter D. DNA methylation dynamics during epigenetic reprogramming in the germline and preimplantation embryos. Genes Dev. 2014;28(8):812-28.

17. Hsiao SH, Lee KD, Hsu CC, Tseng MJ, Jin VX, Sun WS, Hung YC, Yeh KT, Yan PS, Lai YY, et al. DNA methylation of the Trip10 promoter accelerates mesenchymal stem cell lineage determination. Biochem Biophys Res Commun. 2010;400(3):305-12.

18. Hsiao SH, Huang TH, Leu YW. Excavating relics of DNA methylation changes during the development of neoplasia. Semin Cancer Biol. 2009;19(3):198-208.

19. Ehrlich M. DNA hypomethylation in cancer cells. Epigenomics. 2009;1(2):239-59.
20. Frigola J, Sole X, Paz MF, Moreno V, Esteller M, Capella G, Peinado MA. Differential DNA hypermethylation and hypomethylation signatures in colorectal cancer. Hum Mol Genet. 2005;14(2):319-26.

21. Teng IW, Hou PC, Lee KD, Chu PY, Yeh KT, Jin VX, Tseng MJ, Tsai SJ, Chang YS, Wu CS, et al. Targeted methylation of two tumor suppressor genes is sufficient to transform mesenchymal stem cells into cancer stem/initiating cells. Cancer Res. 2011;71(13):4653-63.

22. Press JZ, De Luca A, Boyd N, Young S, Troussard A, Ridge Y, Kaurah P, Kalloger SE, Blood KA, Smith M, et al. Ovarian carcinomas with genetic and epigenetic BRCA1 loss have distinct molecular abnormalities. BMC Cancer. 2008;8:17.

23. Gifford G, Paul J, Vasey PA, Kaye SB, Brown R. The acquisition of hMLH1 methylation in plasma DNA after chemotherapy predicts poor survival for ovarian cancer patients. Clin Cancer Res. 2004;10(13):4420-6.

24. Lehmann U, Celikkaya G, Hasemeier B, Langer F, Kreipe H. Promoter hypermethylation of the death-associated protein kinase gene in breast cancer is associated with the invasive lobular subtype. Cancer Res. 2002;62(22):6634-8

25. Yamaguchi S, Asao T, Nakamura J, Ide M, Kuwano H. High frequency of DAP-kinase gene promoter methylation in colorectal cancer specimens and its identification in serum. Cancer Lett. 2003;194(1):99-105.

26. Tang X, Wu W, Sun SY, Wistuba II, Hong WK, Mao L. Hypermethylation of the death-associated protein kinase promoter attenuates the sensitivity to TRAlL-induced apoptosis in human non-small cell lung cancer cells. Mol Cancer Res. 2004;2(12):685-91.

27. Kato K, lida S, Uetake H, Takagi Y, Yamashita T, Inokuchi M, Yamada H, Kojima K, Sugihara K. Methylated TMS1 and DAPK genes predict prognosis and response to chemotherapy in gastric cancer. Int J Cancer. 2008;122(3):603-8.

28. Finnberg N, El-Deiry WS. TRAIL death receptors as tumor suppressors and drug targets. Cell Cycle. 2008;7(11):1525-8.

29. Jeong DH, Youm MY, Kim YN, Lee KB, Sung MS, Yoon HK, Kim KT. Promoter methylation of p16, DAPK, CDH1, and TIMP-3 genes in cervical cancer: correlation with clinicopathologic characteristics. Int J Gynecol Cancer. 2006;16(3):1234-40.

30. Chekhun VF, Mykytenko DO, Luk'ianova N, Pohribnyi IP. [Correction of DNA methylation disorder as a possible way to modulation of malignant cells drug resistance]. Ukr Biokhim Zh (1999). 2006;78(6):5-14.

31. Baker EK, El-Osta A. The rise of DNA methylation and the importance of chromatin on multidrug resistance in cancer. Exp Cell Res. 2003;290(2):177-94

32. Chen SJ, Kuo CC, Pan HY, Tsou TC, Yeh SC, Chang JY. Mechanistic basis of a combination D-penicillamine and platinum drugs synergistically inhibits tumor growth in oxaliplatin-resistant human cervical cancer cells in vitro and in vivo. Biochem Pharmacol. 2015;95(1):28-37.

33. Onda K, Suzuki R, Tanaka S, Oga H, Oka K, Hirano T. Decitabine, a DNA methyltransferase inhibitor, reduces P-glycoprotein mRNA and protein expressions and increases drug sensitivity in drug-resistant MOLT4 and Jurkat cell lines. Anticancer Res. 2012:32(10):4439-44.

34. Sun S, Huang YW, Yan PS, Huang TH, Lin S. Preprocessing differential methylation hybridization microarray data. Biodata Min. 2011;4:13.

35. Yan PS, Potter D, Deatherage DE, Huang TH, Lin S. Differential methylation hybridization: profiling DNA methylation with a high-density CpG island microarray. Methods Mol Biol. 2009;507:89-106.

36. Liu G, Liu YJ, Lian WJ, Zhao ZW, Yi T, Zhou HY. Reduced BMP6 expression by DNA methylation contributes to EMT and drug resistance in breast cancer cells. Oncol Rep. 2014;32(2):581-8.

37. Xinxin S, Yujie S. Aberrant DNA methylation and drug resistance of tumor cells. Yi Chuan. 2014;36(5):411-9.

38. Maeda O, Ando T, Ohmiya N, Ishiguro K, Watanabe O, Miyahara R, Hibi Y, Nagai T, Yamada K, Goto H. Alteration of gene expression and DNA methylation in drug-resistant gastric cancer. Oncol Rep. 2014;31(4):1883-90.

39. Candelaria M, de la Cruz-Hernandez E, Taja-Chayeb L, Perez-Cardenas E, Trejo-Becerril C, Gonzalez-Fierro A, Chavez-Blanco A, Soto-Reyes E, Dominguez G, Trujillo JE, et al. DNA methylation-independent reversion of gemcitabine resistance by hydralazine in cervical cancer cells. PLoS One. 2012;7(3):e29181.

40. Lin YS, Shaw AY, Wang SG, Hsu CC, Teng IW, Tseng MJ, Huang TH, Chen CS, Leu YW, Hsiao SH. Identification of novel DNA methylation inhibitors via a two-component reporter gene system. J Biomed Sci. 2011;18:3. 
41. Lee OK, Kuo TK, Chen WM, Lee KD, Hsieh SL, Chen TH. Isolation of multipotent mesenchymal stem cells from umbilical cord blood. Blood. 2004;103(5):1669-75.

42. Hsu CC, Li HP, Hung YH, Leu YW, Wu WH, Wang FS, Lee KD, Chang PJ, Wu CS, Lu YJ, et al. Targeted methylation of CMV and E1A viral promoters. Biochem Biophys Res Commun. 2010;402(2):228-34.

43. Yan PS, Venkataramu C, Ibrahim A, Liu JC, Shen RZ, Diaz NM, Centeno B, Weber F, Leu YW, Shapiro CL, et al. Mapping geographic zones of cancer risk with epigenetic biomarkers in normal breast tissue. Clin Cancer Res. 2006;12(22):6626-36.

44. Leu YW, Rahmatpanah F, Shi H, Wei SH, Liu JC, Yan PS, Huang TH. Double RNA interference of DNMT3b and DNMT1 enhances DNA demethylation and gene reactivation. Cancer Res. 2003;63(19):6110-5.

45. Koh KP, Rao A. DNA methylation and methylcytosine oxidation in cell fate decisions. Curr Opin Cell Biol. 2013;25(2):152-61.

46. De Carvalho DD, You JS, Jones PA. DNA methylation and cellular reprogramming. Trends Cell Biol. 2010;20(10):609-17.

47. Jones PA, Baylin SB. The fundamental role of epigenetic events in cancer. Nat Rev Genet. 2002;3(6):415-28
48. Siegmund KD, Marjoram P, Woo YJ, Tavare S, Shibata D. Inferring clonal expansion and cancer stem cell dynamics from DNA methylation patterns in colorectal cancers. Proc Natl Acad Sci USA. 2009;106(12):4828-33.

49. Wermann H, Stoop H, Gillis AJ, Honecker F, van Gurp RJ, Ammerpohl O, Richter J, Oosterhuis JW, Bokemeyer C, Looijenga LH. Global DNA methylation in fetal human germ cells and germ cell tumours: association with differentiation and cisplatin resistance. J Pathol. 2010;221(4):433-42.

50. Chuang JC, Warner SL, Vollmer D, Vankayalapati H, Redkar S, Bearss DJ, Qiu X, Yoo CB, Jones PA. S110, a 5-aza-2'-deoxycytidine-containing dinucleotide, is an effective DNA methylation inhibitor in vivo and can reduce tumor growth. Mol Cancer Ther. 2010;9(5):1443-50.

51. Leshchenko W, Kuo PY, Shaknovich R, Yang DT, Gellen T, Petrich A, Yu Y, Remache Y, Weniger MA, Rafiq S, et al. Genomewide DNA methylation analysis reveals novel targets for drug development in mantle cell lymphoma. Blood. 2010;116(7):1025-34.

52. Yang $X$, Lay $F$, Han H, Jones PA. Targeting DNA methylation for epigenetic therapy. Trends Pharmacol Sci. 2010;31(11):536-46.

\section{Submit your next manuscript to BioMed Central and take full advantage of:}

- Convenient online submission

- Thorough peer review

- No space constraints or color figure charges

- Immediate publication on acceptance

- Inclusion in PubMed, CAS, Scopus and Google Scholar

- Research which is freely available for redistribution

Submit your manuscript at

www.biomedcentral.com/submit

C Biomed Central 